\title{
QUADRINIZANDO SHAKESPEARE: MACBETH, POR KATE BEATON
}

\author{
Shakespeare into Comics: Macbeth, by Kate Beaton
}

\author{
Marilda Lopes Pinheiro QUELUZ \\ Universidade Tecnológica Federal do Paraná \\ pqueluz@gmail.com \\ Rebeca Pinheiro QUELUZ \\ Doutora pela Universidade Federal do Paraná \\ rebecaqueluz@gmail.com
}

RESUMO: Este artigo analisa tiras cômicas de Macbeth publicadas por Kate Beaton. A cartunista tematiza, em seu blog, figuras históricas e personagens fictícios, sobretudo, da literatura ocidental. Em "The Scottish Play", Beaton comenta passagens específicas da peça shakespeariana. A base de nossa análise serão os trabalhos de Linda Hutcheon, Julie Sanders, Sarah Sillin e Daniel Marrone. Queremos refletir sobre o diálogo entre a literatura e os quadrinhos, procurando compreender como Beaton explora a linguagem da narrativa sequencial e as mídias sociais para atualizar as peças do dramaturgo inglês e construir estratégias de aproximação com os leitores. PALAVRAS-CHAVE: Shakespeare em quadrinhos; Macbeth; Kate Beaton.

ABSTRACT: This paper looks at Macbeth's comic strips published by Kate Beaton. On her blog, the cartoonist addresses historical figures and fictional characters, predominantly from Western literature. In "The Scottish Play", Beaton comments on specific passages in the Shakespearean play. Our analysis is grounded on the works of Linda Hutcheon, Julie Sanders, Sarah Sillin and Daniel Marrone. We want to reflect on the dialogue between literature and comics, trying to understand how Beaton explores the language of sequential narrative and social media in order to update the plays of the English playwright and build strategies to approach readers. KEYWORDS: Shakespeare into comics; Macbeth; Kate Beaton. 


\section{INTRODUÇÃO}

Este texto tem por objetivo analisar alguns quadrinhos feitos pela cartunista, historiadora e antropóloga, Kate Beaton, considerando as estratégias de apropriação da peça Macbeth, de William Shakeaspeare. A autora, que começou a postar seu trabalho em 2007 em um blog chamado Hark! A Vagrant, <https://beatonna.livejournal.com/>, atualmente publica suas tiras com alguma frequência no website de mesmo nome, $<$ http:// www.harkavagrant.com/>, que está online desde maio de 2008. A quadrinista canadense também criou contas em outras redes sociais, como o Facebook, o Instagram e o Twitter para ajudar a divulgá-las. Uma parte desses seus trabalhos foi publicada em dois livros impressos: Hark! A Vagrant (2011) e Step Aside Pops: A Hark! A Vagrant Collection (2015).

Sua obra apresenta como tema principal figuras históricas (como James Joyce, Ada Lovelace, Jane Austen, Napoleão, Mary Shelley, Jules Verne), personagens fictícios (Drácula, Sherlock Holmes, Robinson Crusoé, Harry Potter, o gato de Cheshire), sobretudo, da literatura ocidental. Nas palavras de Sarah Sillin (2017, p. 194-195),

Os quadrinhos de Beaton, que satirizam tudo, de Henrique VIII à mídia de hoje, incluem representações engenhosas de figuras políticas e literárias americanas como: Ben Franklin, Nathaniel Hawthorne e Ida B. Wells. Suas representações deliciosamente abundantes da cultura do século XIX não apenas insistem que os leitores reconheçam esse passado como influente e generativo, mas também nos convidam a rir dele ${ }^{1}$.

Sillin também aponta que a quadrinista tem um apego ao século XIX, evidenciando um fascínio por essa era que a sintoniza com suas falhas e defeitos. Os leitores, por sua vez, sentem uma afinidade nerd por esse apego. Sillin se inclui entre seus leitores nerds: "além de converter novos públicos que não dispõem de investimento prévio na cultura do século XIX, Hark! A Vagrant evoca uma segunda camada de prazer para leitores que são aficionados por história ou literatura. Nós nos identificamos com Beaton como alguém que compartilha nossas inclinações ${ }^{2 "}$ (SILLIN, 2017, p. 195, grifos nossos). Ela compara $\mathrm{o}$ ato de ler os quadrinhos de Beaton com o ato de tomar cerveja com um amigo que compartilha as mesmas preferências e que se diverte falando sobre o que está bebendo sem parecer esnobe.

Outra questão importante no trabalho de Beaton diz respeito à forma como ela lida com diferentes referências culturais. Seus quadrinhos "convey their charming fascination 
with the past through concise, unexpected juxtapositions: of word and image, highbrow cultural references and lowbrow scatological humor, "silly" form and "serious" historical subject" (SILLIN, 2017, p. 194).

No que concerne às obras de William Shakespeare, a quadrinista dedicou diversas tiras para homenagear o dramaturgo inglês. Em seu arquivo é possível acessar as seguintes entradas: Macbeth, King Lear, Caesar part 1, Caesar part 2, Richard III, Hamlet. Para esse trabalho, nossa atenção será direcionada especialmente para os quadrinhos referentes a Macbeth.

As análises serão feitas a partir do embasamento teórico dos trabalhos de Linda Hutcheon sobre paródia, dos estudos de Julie Sanders sobre apropriação e dos textos de Sarah Sillin e de Daniel Marrone sobre os quadrinhos de Kate Beaton. Queremos propor uma reflexão acerca do diálogo entre a literatura e os quadrinhos, procurando compreender como Kate Beaton explora a linguagem da narrativa sequencial e as mídias sociais para atualizar as peças do dramaturgo inglês e construir estratégias de aproximação com os leitores e de incentivo à leitura a novos públicos das redes sociais.

\section{QUEM É KATE BEATON?}

Kathryn Moira Beaton nasceu em 1983 em Mabou, Nova Scotia, no Canadá. Fazia parte de uma comunidade pequena, onde todos se conheciam e onde ela era lembrada como a moça que sabia desenhar. Na infầncia teve acesso a histórias em quadrinhos da editora Archie, a Foxtrot, de Bill Amend, a Peanuts, de Charlie Schulz, a quadrinhos que encontrava nos poucos jornais que circulavam em sua cidade e a quadrinhos sobre a vida de santos (como a da freira canadense Marguerite Bourgeoys, que a cartunista menciona em uma entrevista de 2015 feita por Chris Mautner) a que tinha acesso na escola. A partir desses quadrinhos foi aprendendo sobre a estrutura da arte sequencial, sobre ritmo e sobre formas de elaborar piadas (MAUTNER, 2015).

Outra fonte de inspiração para o desenvolvimento de seu trabalho foi o professor, cientista político, escritor e humorista canadense Stephen Leacock (1869-1944). Tal autor escreveu textos paródicos com poucas páginas, livros com capítulos curtos, que depreendiam de modo aguçado o humor.

É relevante mencionar que Kate Beaton estudou História e Antropologia na Mount Allison University, em Sackville, New Brunswick e se formou em 2005. No terceiro ano da faculdade, começou a confeccionar seus quadrinhos para o jornal do campus, The Argosy (onde escrevia igualmente para a seção de humor, <http://www.harkavagrant. 
com/index.php?id=343>). Segundo Beaton, Quiz Time era uma seção que continha:

dez perguntas com respostas falsas. Era um quebra-cabeça divertido de montar porque às vezes as respostas falsas se relacionavam entre si e eram uma piada dentro de uma piada. De qualquer forma, comecei a fazer histórias em quadrinhos e a escrever o questionário de uma maneira que lembrava Hark! A Vagrant. Eles eram sobre história e eu podia ser sagaz e queria aquele humor inteligente ao invés daquele humor grosseiro 3 (BEATON apud MAUTNER, 2015).

Para pagar o empréstimo estudantil, trabalhou em alguns museus, sendo um deles o Maritime Museum of British Columbia. Em setembro de 2007 começou a postar seus quadrinhos em um LiveJournal e, um ano depois, pediu demissão do último emprego para viver de sua arte. Na tira de número 69 (Figura 01), intitulada Uma jovem profissional (A Young Professional), publicada no blog Hark! A Vagrant, Beaton apresenta algumas considerações sobre seu trabalho no museu:

\footnotetext{
${ }^{3}$ Tradução nossa. No original: "ten questions with fake answers. It was a fun puzzle to put together, because sometimes the fake answers would relate to each other and be a joke within a joke. Anyway, I started to make comics and write the quiz in ways that resembled Hark! A Vagrant. They were about history and I could be clever and I wanted that smart humor instead of that crass humor".
} 
Figura 01: Tira 69 - A Young Professional.

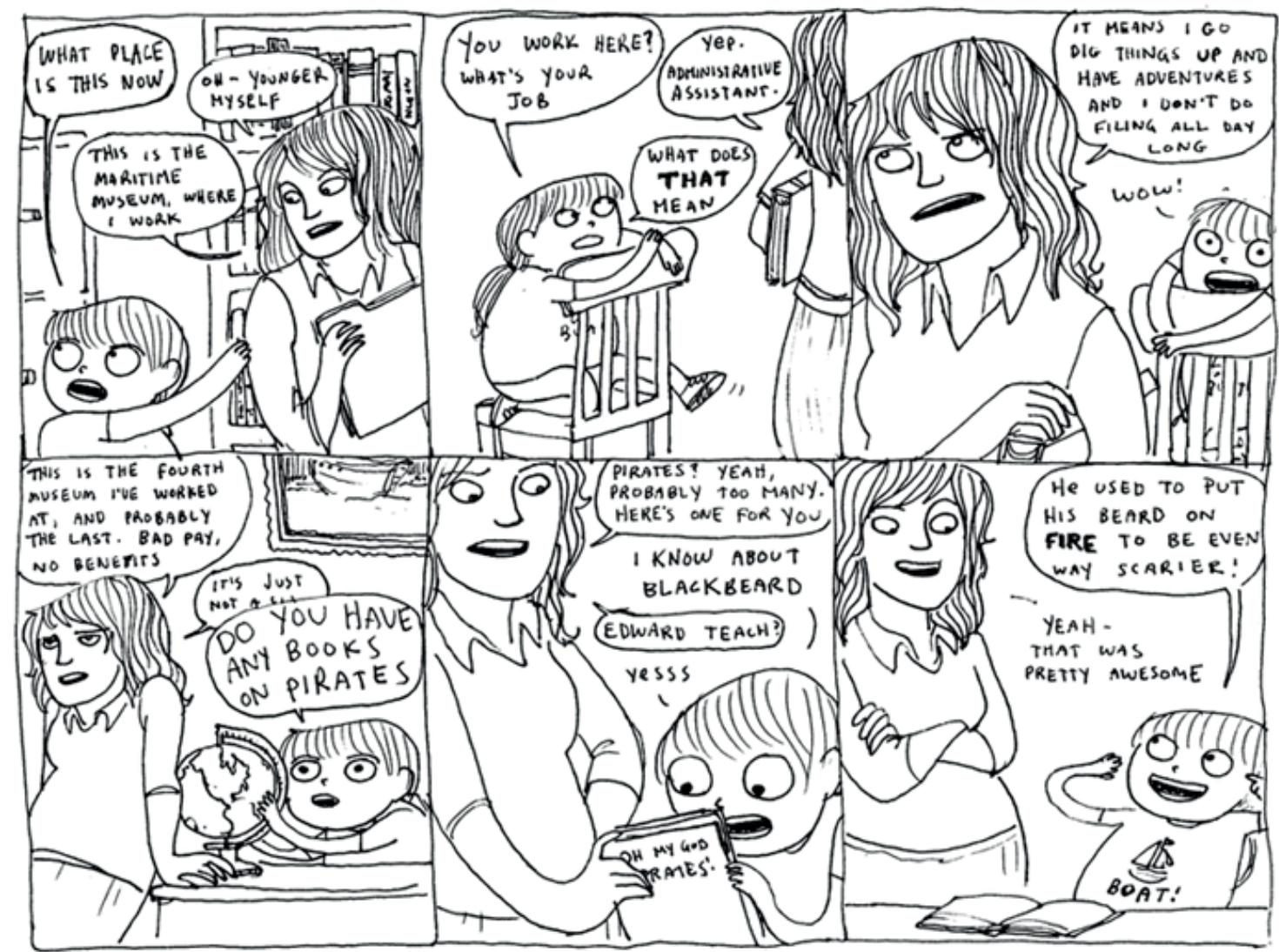

Fonte: $<$ http://www.harkavagrant.com/index.php?id=69>. Acesso: 28 abr. 2019.

Ela se coloca na tira (como personagem) e se identifica com uma versão mais nova dela mesma. Revisita o seu passado de assistente administrativa, lamenta o pouco que ganha e a falta de benefícios, contrapondo as questões materiais e de sobrevivência com os motivos que realmente importam: a paixão pela história, pelos estudos, pelo mundo de aventuras dos livros. O diálogo e a expressão corporal sugerem um momento para resgatar as motivações e os sonhos que estavam esquecidos no cotidiano do trabalho. Parece apontar, ainda, para a trajetória de busca de equilíbrio entre a diversão e a seriedade de ler, pesquisar, escrever.

Suas tiras cômicas começaram a ser publicadas em lugares como a Harper's Magazine (a edição de setembro de 2010), a revista The Walrus (fez a capa da edição de julho/ agosto 2012), a revista The New Yorker (na edição de 10 a 17 de agosto de 2015), o jornal The Guardian (há reportagens, entrevistas, resenhas de seus livros e, inclusive, 
ilustrações de seus cadernos de esboços) eem antologias como The Best American Comics (edições de 2011, 2013 e 2016). Seu trabalho apareceu lado a lado dos quadrinhos de Chris Ware, Joe Sacco, Julia Wertz, Alison Bechdel e Craig Thompson.

Beaton desenhou para a Marvel tiras de personagens como a Vampira (dos X-Men) e Kraven - O Caçador (vilão que aparece nas histórias do Homem-Aranha). Elas saíram na coletânea Strange Tales II (2010) ${ }^{4}$. Além disso, a cartunista publicou na Thought Bubble Anthology: 10 Years of Comics (2016), uma antologia que celebrava o décimo aniversário do Thought Bubble Festival, ocorrido em Leeds, na Inglaterra. Nela estavam, entre outros quadrinistas: Gabriel Bá, Gabriel Bautista, Emily Carrol, Emma Ríos. Também fez um Google Doodle (https://www.google.com/doodles/henrietta-edwards-165th-birthday) da Henrietta Edwards (1849-1931) para comemorar seu 165ºniversário.

No que concerne à publicação de livros, Kate Beaton iniciou tal empreitada com o lançamento de Never Learn Anything From History - A Collection of Comics By Kate Beaton em 2009. Em 2011, publicou Hark! A Vagrant, que obteve 65.000 vendas. Em seguida, saiu um segundo livro com uma coletânea de seu blog, intitulado Step Aside Pops - A Hark! A Vagrant Collection (2015). Ambas as obras foram publicadas pela editora Drawn \& Quarterly de Montreal. Logo depois, a quadrinista se embrenhou na literatura infantil e lançou dois títulos: The Princess and the Pony (2015) e King Baby (2016).

Por fim, Beaton ganhou o Doug Wright Award for Canadian Comics como a Best Emerging Talent em 2009 e em 2012 conseguiu o mesmo prêmio na categoria Best Book, com o livro Hark! A Vagrant. Recebeu, ainda, o Harvey Award nas categorias Best Online Comics Work (2011 e 2012), Special Award for Humor in Comics (2012) e Best Cartoonist (2012); o Ignatz Award pelo Outstanding Online Comic (2011) e o Eisner Award pela Best Humor Publication (2016). Foi nomeada, tanto em 2009 como em 2010, para o Joe Shuster Awards. 


\section{APROPRIAÇÃO E PARÓDIA}

Julie Sanders, em uma obra chamada Adaptation and Appropriation (2006) destaca o caráter intertextual da obra de arte, a partir das ideias de Roland Barthes (1981) de que todo texto é um intertexto, e de Julia Kristeva (1980), de que os textos são permutações de $\operatorname{textos}^{6}$ - tendo esta última se inspirado no conceito de polifonia ${ }^{7}$ de Mikhail Bakhtin (2003). O teórico russo, por sua vez, defendia que todo discurso é formado por outros discursos e que toda fala é habitada por vozes diversas.

Nas palavras de Julie Sanders (2006, p. 14),

Os textos se alimentam mutuamente e criam outros textos e outros estudos críticos; a literatura cria outra literatura. Parte do puro prazer da experiência de leitura deve ser a tensão entre o conhecido e o novo e o reconhecimento tanto da similaridade como da diferença, entre nós mesmos e entre os textos. O prazer existe e persiste, então, no ato de ler e reler (e reler) ${ }^{8}$.

Isto posto, a intertextualidade se torna explícita em todas as produções artísticas que se valem da apropriação e está ligada às práticas sociais de determinados contextos históricos. Ela ocorre por meio de referências diretas ou indiretas a outros textos, alusões a autores, a estilos de escrita, epígrafes, paráfrases e paródias. Dialoga com a tradição, com a herança cultural e com a contemporaneidade.

Em sua obra, a autora apresenta os conceitos de adaptação e de apropriação. A adaptação, na visão de Sanders, é um processo que geralmente envolve a transição de um gênero para outro, ou seja, de romances para filmes, teatro para musicais, a dramatização da poesia narrativa ou da ficção em prosa, dentro das possibilidades. Outro aspecto mencionado por Sanders é o fato de a adaptação ser uma reinterpretação de um texto em um novo contexto ou ainda uma realocação de um texto anterior para outra cultura ou outro local, o que pode ou não modificar o gênero em que o novo texto será realizado. Longe de ser imitação, cópia ou repetição, a adaptação é um processo complexo, criativo, permeado de escolhas e intenções. Cria seus próprios textos e dialoga com outras adaptações além do seu texto de partida.

Já a apropriação difere da adaptação. Conforme Sanders (2006, p. 26),

uma adaptação sinaliza um relacionamento com um texto fonte ou original. Por outro lado, a apropriação frequentemente afeta uma jornada mais decisiva distanciada da fonte para um produto e domínio 
cultural totalmente novo. Isso pode ou não envolver uma mudança genérica e ainda pode exigir a justaposição intelectual de (pelo menos) um texto contra o outro que sugerimos ser central para a experiência de adaptação e leitura. Mas o(s) texto(s) apropriado(s) não é(são) sempre tão claramente sinalizado(s)ou reconhecido(s) como no processo adaptativo 9

Para exemplificar a sua diferenciação, a autora cita o musical Kiss me Kate (1953), que a seu ver é ao mesmo tempo uma adaptação e uma apropriação. O musical em si é uma adaptação da peça shakespeariana, A megera domada, enquanto que a história que se desenvolve nos bastidores é uma apropriação.

Ainda, segundo Sanders, tanto a adaptação como a apropriação retomam e perpetuam o cânone, ao mesmo tempo em que contribuem para sua reformulação e sua expansão. A reescrita, para ela, "invariavelmente transcende a mera imitação, servindo, ao invés disso, na capacidade de literatura incremental, acrescentando, suplementando, improvisando, inovando ${ }^{10}$ " (SANDERS, 2006, p. 12), de tal modo que o objetivo não é criar uma réplica, mas uma estrutura complexa, uma expansão do texto anterior em vez de uma redução.

Sobre a apropriação, Erika Viviane Costa Vieira, em "Espectralizações de Hamlet: aproximações entre a teoria da tradução e a apropriação literária”, destaca que

\begin{abstract}
é um termo que denota uma relação intertextual menos explícita, mas mais questionadora, hostil, ou até mesmo de caráter mais subversivo devido, principalmente, à postura crítica que adota. Enquanto a adaptação presta uma homenagem ao texto fonte, a apropriação o desafia, evocando, assim, uma ruptura com a tradição, seus valores e sua hierarquia (VIEIRA, 2012, p. 173-174).
\end{abstract}

Kate Beaton, ao elaborar tiras cômicas a partir de trechos das peças de William

\footnotetext{
${ }^{9}$ Tradução nossa. No original: "an adaptation signals a relationship with an informing sourcetext or original. On the other hand, appropriation frequently affects a more decisive journey away from the informing source into a wholly new cultural product and domain. This may or may not involve a generic shift, and it may still require the intellectual juxtaposition of (at least) one text against another that we have suggested is central to the reading and spectating experience of adaptations. But the appropriated text or texts are not always as clearly signaled or acknowledged as in the adaptive process".

${ }^{10}$ Tradução nossa. No original: "invariably transcends mere imitation, serving instead in the capacity of incremental literature, adding, supplementing, improvising, innovating".
} 
Shakespeare, apropria-se de suas falas, personagens e enredos, para inserir o seu ponto de vista sobre as mesmas. Por vezes, a cartunista tece comentários acerca das figuras de linguagem, brinca com os sentidos das palavras, introduz elementos anacrônicos, com o intuito de gerar riso. Ela vai além do que estava posto no texto de partida.

Outra forma de pensar o trabalho de Beaton é a partir do viés da paródia. Em Uma teoria da paródia, Linda Hutcheon (1985, p. 13) destaca que a paródia é "um dos modos maiores da construção formal e temática de textos", é um ato crítico de reavaliação e acomodação, uma forma de discurso interartístico. Longe de ser parasitária e derivativa, uma imitação ridicularizadora, a paródia, no entender de Hutcheon, é um processo de transferência e de reorganização do passado que tende a desmistificar o "nome sacrossanto do autor" e a dessacralizar a origem do texto (HUTCHEON, 1985, p. 16).

Nessa perspectiva, a paródia é vista como uma "forma de imitação caracterizada por uma inversão irônica, nem sempre às custas do texto parodiado" (HUCTHEON, 1985, p. 17). Ela é uma repetição com um distanciamento crítico, que aponta para as diferenças ao invés das semelhanças. É uma abordagem criativa e produtiva da tradição. Nas palavras de Hutcheon (1985, p. 19), a paródia "é uma confrontação estilística, uma recodificação moderna que estabelece a diferença no coração da semelhança”.

\section{ANACRONISMO DELIBERADO E METAFICÇÃO HISTORIOGRÁFICA}

De acordo com Daniel Marrone (2018), em seus quadrinhos, Beaton contrasta eventos históricos com uma sensibilidade contemporânea, justapondo passado e presente de forma inesperada, trazendo luz a ambos. Nesse sentido, Marrone sugere que o que Beaton faz é uma variação da técnica que Jorge Luis Borges atribui a Pierre Menard: o anacronismo deliberado. O autor se explica:

Em "Pierre Menard, Autor do Quixote", Borges elogia o autor homônimo por sua reescrita palavra por palavra tremendamente ambiciosa, inacabada e espontânea de Don Quixote. O projeto de Menard é invisível, consistente: ao se imaginar na mente de Cervantes ele produz um Quixote idêntico. Em comparação, Beaton afirma seu próprio ponto de vista em um trabalho que é perfeitamente visível: através de descontinuidades cronológicas, ela mostra as costuras da história. Seu anacronismo deliberado produz uma história que está constantemente se dobrando sobre si mesma ${ }^{11}$ (MARRONE, 2018, p. 176).

\footnotetext{
${ }^{11}$ Tradução nossa. No original: "In "Pierre Menard, Author of the Quixote", Borges lauds the eponymous author for his tremendously ambitious, unfinished, spontaneous word-for-word rewriting of Don Quixote. Menard's project is invisible, seamless: by imagining himself into the
} 
Para exemplificar essa técnica, pensemos em duas tiras, a primeira de Hamlet e a segunda de Júlio César. A tira referente ao príncipe dinamarquês, intitulada The ghost explains ( $\mathrm{O}$ fantasma explica), traz à tona a questão do regicídio de Hamlet pai. Nela, o fantasma do rei Hamlet explica para o filho que ele havia sido assassinado com um veneno. O filho, surpreso, afirma desconhecer essa informação. Indignado, o monarca pergunta se não havia sido realizada uma autópsia no corpo e de que as pessoas pensavam que ele morreu. O humor se revela no terceiro e último quadro, quando Hamlet filho afirma que eles estão na Idade Média e que a crença era de que as pessoas morriam por estar vivas. Neste caso, Beaton insere uma questão contemporânea (pertencente à ciência forense) em um contexto em que tal ciência ainda não era praticada.

Sobre esta questão, Sarah Sillin (2017, p. 195) destaca que Kate Beaton "usa o os jogos de palavras e imagens dos quadrinhos para entrelaçar representações do passado (por exemplo, desenhos de personagens em trajes de época) com lembretes de que ela está escrevendo do presente (especialmente aparente em seu diálogo) ${ }^{12}$ ".

Já a segunda tira, chamada Julius Caesar part one (Júlio César parte um), perpassa o aviso que César recebeu sobre os idos de março. César questiona essa afirmação, buscando entender o que aconteceria nesse período. Respondem-lhe vagamente, afirmando que ele deveria usar algo confortável, talvez pijama e ele determina que assim o fará. Quando Brutus o trai e o apunhala, César cai morto e, por baixo da toga, observa-se que ele estava de pijama de gladiadores. Beaton insere uma vestimenta contemporânea na trama que atua como elemento gerador de humor. São questões banais ou pequenas que nos fazem estabelecer relações entre o período em que aconteceu determinado fato e o que vivemos hoje.

Desse modo, podemos pensar, conforme propõe Marrone (2018), que o trabalho da quadrinista age como um lembrete útil que a história é uma construção, uma constelação de narrativas sobre o passado que são sujeitas a revisão, repúdio e mesmo a uma certa ridicularização. Apesar de qualquer impulso que tenha em direção à imparcialidade, a história sempre vai apresentar um ponto de vista: é o passado visto de um momento

mind of Cervantes, he produces an identical Quixote. By comparison, Beaton asserts her own point of view in work that is highly visible: through chronological discontinuities, she shows the seams of history. Her deliberate anachronism produces a history that is constantly folding over on itself".

${ }^{12}$ Tradução nossa. No original: "uses comics' interplay of words and images to interweave depictions of the past (e.g., drawings of characters in period dress) with reminders that she is writing from the present (especially apparent in her dialogue)". 
presente. Como reflete Marrone, ao colocar em primeiro plano a tensão passado-presente, Beaton revela o anacronismo inerente da história como um discurso.

Outra questão pertinente no trabalho de Kate Beaton diz respeito à metaficção historiográfica como proposta por Linda Hutcheon. Consoante a autora, o termo se refere a uma ficção que é auto reflexiva e que está alicerçada em realidades históricas, sociais e políticas. A metaficção historiográfica se apropria de personagens e/ou acontecimentos históricos entendidos como "verdadeiros" para problematizá-los. A questão que se levanta é o que exatamente pode ser lido como verdade ou ficção. Dito de outra forma, Hutcheon entende que tanto a história como a ficção são construtos linguísticos:

As duas são identificadas como construtos linguísticos, altamente convencionalizadas em suas formas narrativas, e nada transparentes em termos de linguagem ou de estrutura; e parecem ser igualmente intertextuais, desenvolvendo os textos do passado com sua própria textualidade complexa [...] a própria história e a própria ficção são termos históricos e suas definições e suas inter-relações são determinadas historicamente e variam ao longo do tempo (HUTCHEON, 1991, p. 141).

Beaton utiliza o anacronismo e a metaficção como recursos para provocar o riso e a reflexão sobre o modo como escrevemos e interpretamos a história, e nos convida a um olhar crítico sobre nossos próprios comportamentos e nossas visões de mundo, parodiando o passado e o presente a um só tempo. 


\title{
HARK! A VAGRANT E THE SCOTTISH PLAY
}

\author{
Segundo Kate Beaton,
}

Chamei meus quadrinhos de Hark! A Vagrant há muito tempo, num esforço de nomear nada em particular, mas também era algo que soou vagamente antigo, oportuno e absurdo [...] É bom que Hark! A Vagrant não significa nada. Quando me pedem para descrever meus quadrinhos, a coisa mais fácil a dizer é que são paródias históricas, literárias ou da cultura pop. Mas, na verdade, os quadrinhos são apenas um reflexo do que eu acho interessante ou do que estou lendo ou pensando [...] no fim, apenas tento pensar em algo engraçado. Com sorte, estamos na mesma página $^{13}$ (BEATON, 2015, p. 5).

A autora divide seu blog em seções: sobre, apoio (support), loja, arquivo, Tumblr, arquivos por categorias. Essa última apresenta suas tiras do seguinte modo: tiras de história, desenhos de história, nonsense de história, literatura, Nancy Drew, msnpaint, nonsense, super-herói, pônei, adolescentes, eumaisjovem (youngerself), capas de [Edward] Gorey.

Em relação ao processo de produção de seus quadrinhos, Beaton afirma que:

Eu desenho com lápis e depois passo uma caneta por cima, é muito simplista. Uso brush pens para as linhas e uso greyscale markers e às vezes aquarela para sombrear [...] Nos últimos tempos, também usei uma mesa digitalizadora, que comecei a usar quando comecei a fazer livros ilustrados. Acho que, no final, o desenho é melhor, mas às vezes o tablet faz o trabalho quando você precisa, e há muito a aprender com os dois lados ${ }^{14}$ (http://www.harkavagrant.com/about.php).

Em um texto para o blog Pizza Island (BEATON, 2011), a cartunista conta que sempre leva consigo papel Bristol, régua, laptop, ipod, um penal com todos os seus lápis, borrachas e canetas pincéis. 
Figura 02: Tira 262 (Agendamento) - The Scottish Play.
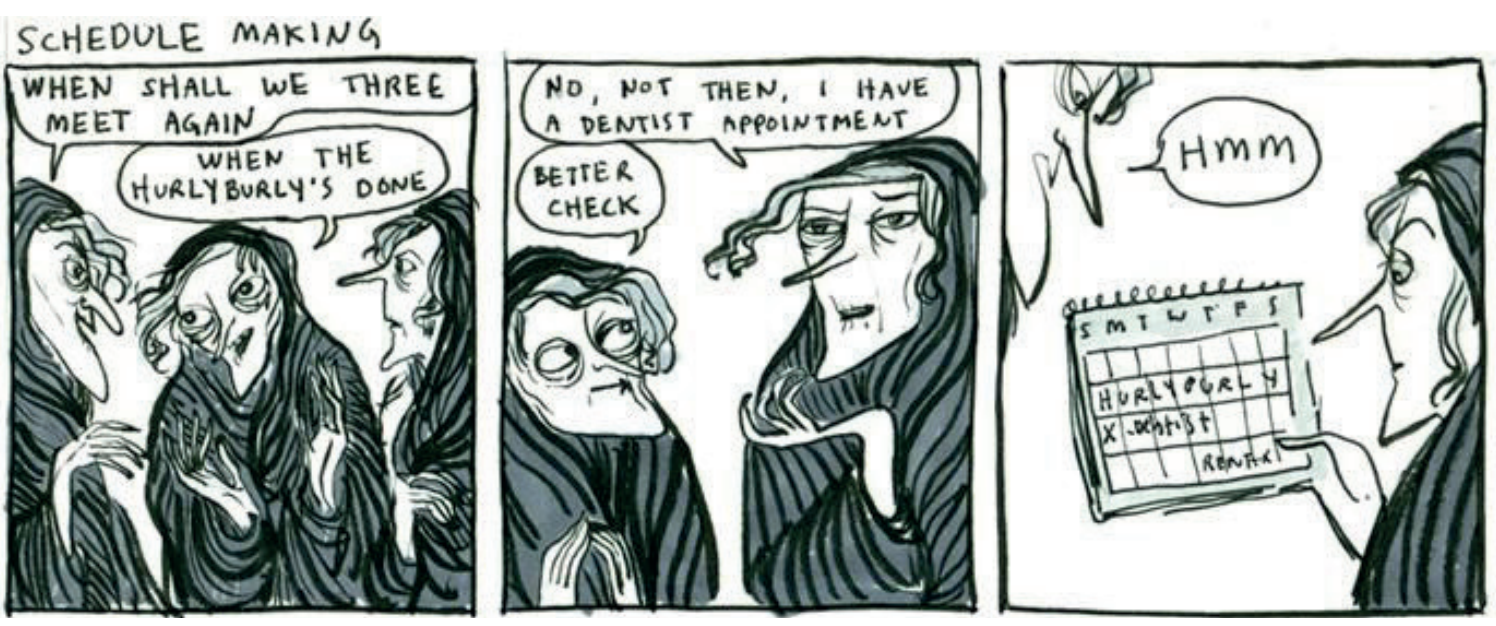

Fonte: $<$ http://www.harkavagrant.com/index.php?id=262 >. Acesso: 28 abr. 2019.

A primeira tira de The Scottish Play (A Peça Escocesa) faz menção à cena inicial de Macbeth (Figura 02), em que temos contato com as três estranhas irmãs e elas conversam sobre seu próximo rendez-vous, que será também um encontro com o protagonista da peça. O humor começa na passagem do primeiro para o segundo quadro e se dá, entre outras questões, pela linguagem. Beaton começa a tira cômica com a fala original das bruxas: "When shall we three meet again" (algo como: "Quando nos encontraremos novamente"?). A segunda bruxa responde: "When the hurlyburly's done" (algo nas linhas de: "Quando a confusão tiver terminado"), brincando com os caminhos tumultuados da trama de Shakespeare. Os leitores familiarizados com a peça esperariam a próxima fala: "When the battle's lost and won" (que, traduzida, seria: "Quando a batalha for ganha e perdida"), ou ainda, o comentário da terceira bruxa: "That will be ere the set of sun" (algo como: "Isso acontecerá antes de o sol se pôr"). Todavia, no segundo quadro temos a fala inesperada da terceira bruxa: "No, not then, I have a dentist appointment" ("Não, não aí, eu tenho dentista"). A informação torna-se ainda mais inusitada se observarmos nos desenhos o fato das bruxas serem, em geral, caracterizadas como banguelas/desdentadas. O desenho de rugas em torno da boca, como no caso da terceira bruxa, costuma evocar, além da velhice, a falta de dentes. Para complementar a piada, a primeira bruxa afirma que seria melhor verificar as datas e, no terceiro quadro, a terceira bruxa segura um calendário com os compromissos assinalados: dentista e confusão (hurlyburly). Beaton introduziu elementos anacrônicos, como a consulta com o dentista e a presença do calendário, na 
peça que se passa na Idade Média escocesa para provocar o riso. A materialidade do calendário usado como uma agenda também pode ser uma ironia sobre a maneira como o futuro é previsto pelas bruxas, como o destino será traçado. Além disso, a linguagem shakespeariana contrasta com o inglês contemporâneo.

A próxima tira (Figura 03) retrata um momento da peça em que Lady Macbeth e seu esposo estão a sós e conversam sobre o regicídio de Duncan (ato 1, cena 7). Lá, Macbeth se deixa convencer pela esposa - que utiliza argumentos sobre covardia e virilidade - de que deveria proceder com o plano do assassinato. Como sugere Frank Kermode (2006, p. 302), "toda essa redefinição de masculinidade a leva [Lady Macbeth] a proclamar sua própria resolução antifeminina; ela mataria o próprio filho", se assim fosse necessário. A personagem, inclusive, afirma que teria a coragem de esmagar o crânio de um recémnascido. Momentos antes de encontrar o seu esposo, Lady Macbeth havia "conclama[do] a noite espessa, envolvida na mais sombria fumarada do inferno" (BRADLEY, 2009, p. 257), e compactuado com as forças das trevas, exigindo que fosse menos feminina e mais cruel, que seu sangue se espessasse a ponto de não sentir remorso e poder cumprir o seu papel no assassinato de Duncan.

Figura 03: Tira 262 (Dessexuai-me, sexuai-me)- The Scottish Play.
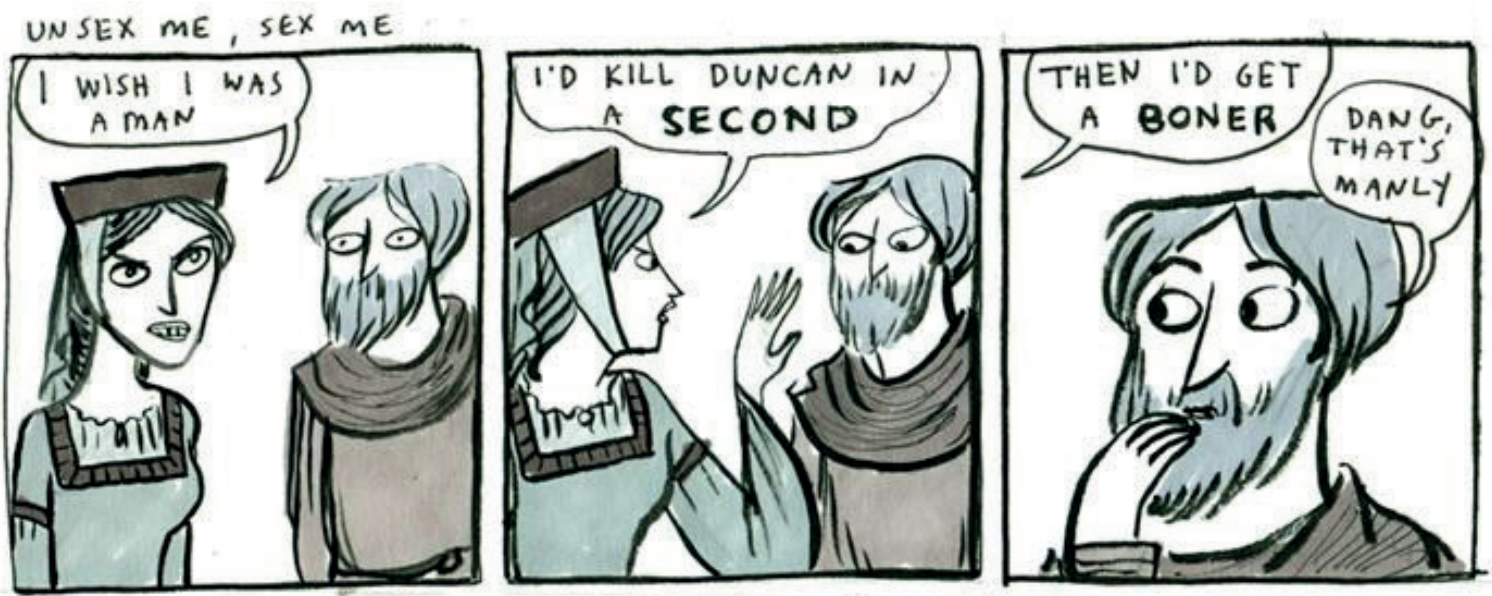

Fonte: $<$ http://www.harkavagrant.com/index.php?id=262 >. Acesso: 28 abr. 2019.

$\mathrm{Na}$ tira, Beaton retoma esse contexto de Macbeth, tornando a cena mais leve e cômica. Sua Lady Macbeth expressa o desejo de ser homem, de possuir a frieza necessária para matar Duncan em um piscar de olhos, e, de ter uma ereção. A autora brinca com a 
associação do prazer com a morte e o prazer sexual. O comentário final de Macbeth acentua a ironia sobre esses signos de masculinidade e virilidade em contraponto a uma suposta delicadeza e ingenuidade feminina. A atitude e o gesto enfático da esposa contrastam com o olhar assustado do marido, reforçando o traço cômico. O título apresenta uma referência à fala de Lady Macbeth ("Come, you spirits/ That tend on mortal thoughts, unsex me here") e à piada sexual contida na tira.

Figura 04: Tira 262 (O pensamento não passa pela cabeça de Macbeth) - The Scottish Play.
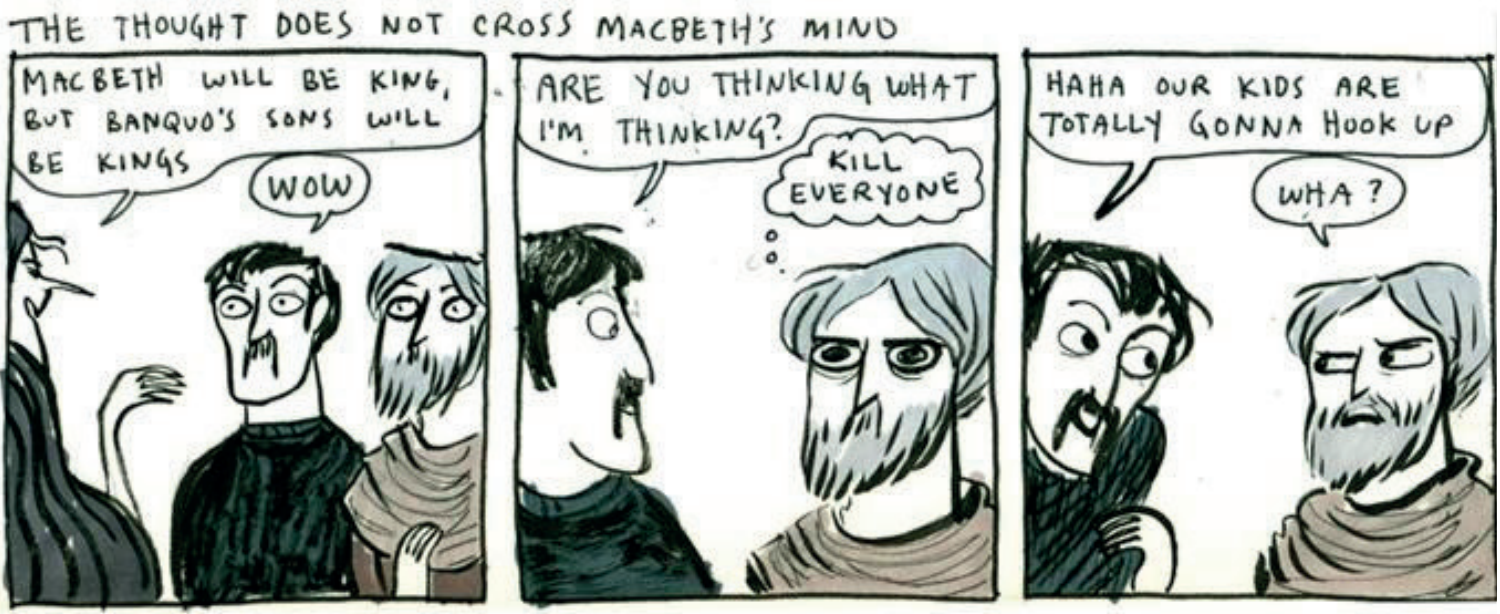

Fonte: $<$ http://www.harkavagrant.com/index.php?id=262 >. Acesso: 28 abr. 2019.

O jogo entre ideias opostas também é explorado nas duas interpretações do destino que aparecem na Figura 04. Nessa tira, o humor é gerado pelo contraste entre as expectativas de Banquo e de Macbeth em relação ao cumprimento das profecias das bruxas. No segundo quadro, quando Banquo pergunta ao companheiro se está pensando na mesma coisa que ele, Macbeth, com um aspecto determinado/concentrado, está arrazoando que terá que matar todos para chegar ao trono, ao contrário de Banquo que imagina um final feliz, com a união dos filhos deles. A indagação de Macbeth, com uma cara desconcertada, "Quê?" reitera o efeito cômico, brincando com os diferentes níveis de ambição dos dois nobres. 
Figura 05: Tira 262 (Em guarda, Macduff, com motivos) - The Scottish Play.

\section{LAY ON MACDUFF, WITH MOTIFS}
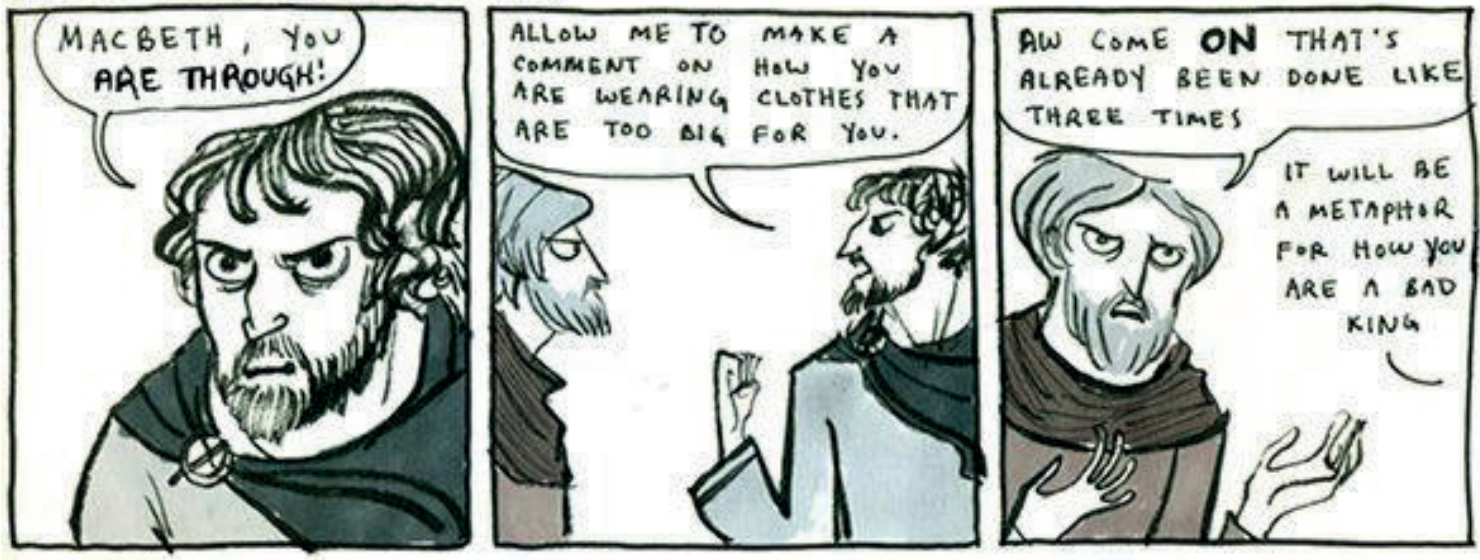

Fonte: $<$ http://www.harkavagrant.com/index.php?id=262>. Acesso: 28 abr. 2019.

$\mathrm{Na}$ figura 05, a tira ironiza as ambições e a busca de poder a qualquer custo; os motivos que levam às guerras e à disputa pelo trono. As roupas que não servem em Macbeth podem ser interpretadas como um reino que não the cabe, que não the é de direito. O humor é gerado através da resposta de Macbeth a Macduff: "isso já foi dito umas três vezes". Ao que Macduff responde: "será uma metáfora sobre como você é um péssimo rei". O título, "Lay on Macduff, with motifs" colabora para o efeito humorístico e remete diretamente a uma fala do protagonista na tragédia shakespeariana, "Lay on, Macduff, and damned be him who first cries 'Hold! enough!' (ato 5, cena 8). Naquele contexto, Macduff e Macbeth estavam prestes a lutar entre si e Macbeth queria que o combate iniciasse imediatamente. Kate Beaton, em sua tira, apropria-se daquela cena e substitui o confronto por uma batalha verbal entre os dois guerreiros com um jogo de metáforas que estão presentes na peça inteira. 
Figura 06: Tira 262 (Macbeth quer ouvi-la novamente) - The Scottish Play.
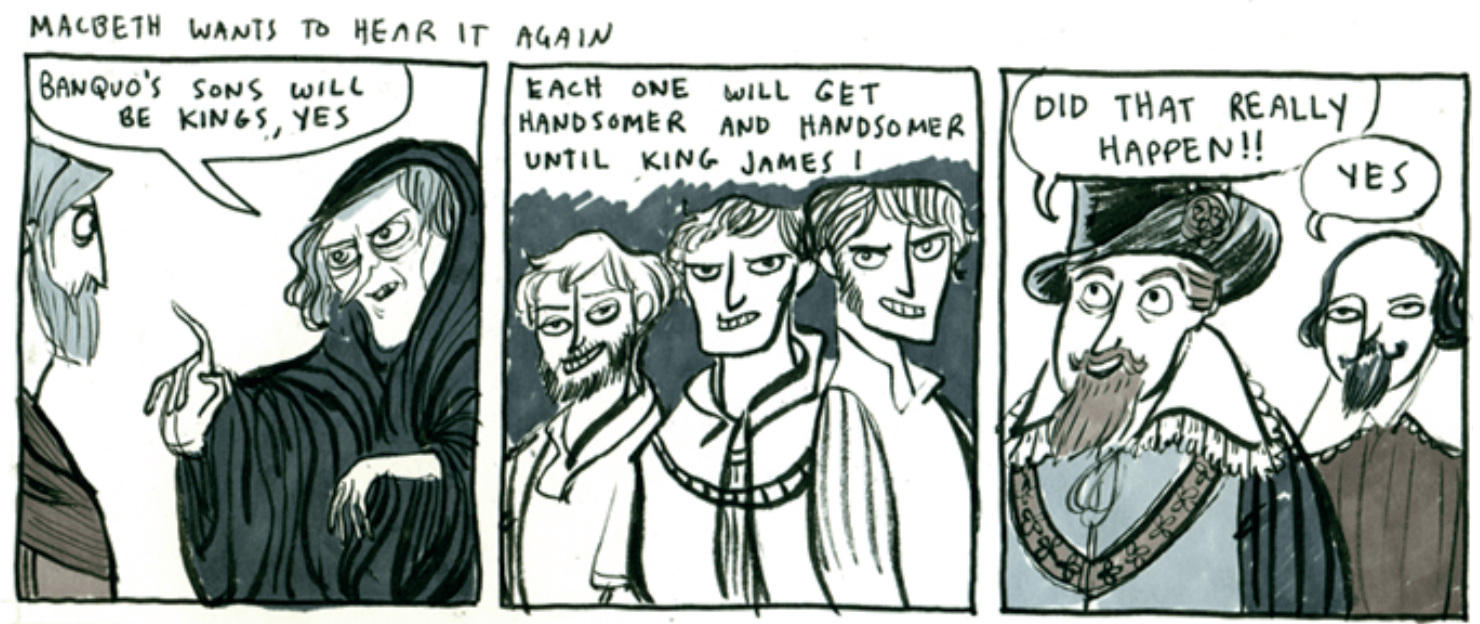

Fonte: $<$ http://www.harkavagrant.com/index.php?id=262>. Acesso: 28 abr. 2019.

Por fim, na Figura 06, Beaton retoma a cena do encontro de Macbeth com as bruxas. A graça está no plot twist que acontece no último quadro: da peça passa-se para o rei Jaime I, que estava assistindo ao espetáculo. A bruxa explicava para Macbeth que os filhos de Banquo seriam reis. Em seguida, explica que cada um seria mais belo que o outro até chegar no rei Jaime I. Nas crônicas de Holinshed, fonte que Shakespeare utilizou para criar sua peça, apontava-se que Jaime I era descendente de Banquo. Shakespeare, para bajular o rei, enaltece as qualidades desse guerreiro na mesma proporção em que cria um Macbeth terrível, traidor, tirano e usurpador. A cartunista, nesta tira, está mostrando um pouco do que havia nos bastidores, como os dramaturgos precisavam adular seus patrocinadores. Trabalha com a metalinguagem para mostrar que o destino dos personagens está nas mãos do autor e com a metaficção, na medida em que imagina um suposto diálogo entre Jaime I e Shakespeare. A construção visual das expressões faciais canastronas dos príncipes no segundo quadrinho e a vaidade estampada no olhar de Jaime II completam a piada.

\section{ALGUMAS CONSIDERAÇÕES}

Na seção intitulada "The Scottish Play", Beaton introduz, através de suas tiras, alguns comentários (em sua maioria) cômicos a respeito de passagens específicas da peça shakespeariana, como: a do encontro das bruxas, a da previsão de que os filhos de Banquo 
serão reis, a da aparição do fantasma de Banquo, a do sonambulismo de Lady Macbeth, a da decapitação do herói-vilão ao final. Em apenas nove tiras, Kate Beaton revisita Macbeth e traz uma leitura crítica, atribuindo novos sentidos à obra shakespeariana. De maneira divertida e inusitada, a cartunista se apropria da estrutura narrativa de Shakespeare e a modifica, transforma e recria acrescentando muitos elementos de ironia.

O traço debochado rompe com o distanciamento e a seriedade de uma obra canônica, autorizando-nos a rir e questionar os clássicos, tornando-nos mais próximos/ íntimos dos textos. Os quadrinhos de Kate Beaton exigem um leitor atento, voraz, erudito, cúmplice de detalhes minuciosos das falas, das cenas, dos personagens.

A autora utiliza expressões ambíguas e contemporâneas para ressaltar os absurdos de violência da tragédia shakesperiana. Sua paródia de trechos de Macbeth provoca deslocamentos de sentido que atualizam as reflexões sobre o destino, as ambições e as paixões humanas.

Por outro lado, Beaton faz pensar sobre nossos comportamentos e costumes do presente, desde nossos hábitos de leitura e de compartilhamento de gostos, preferências, autores e personagens pelas redes sociais, até o modo como nossa sociedade se organiza em torno de hierarquias de gênero e de classe, de relações assimétricas de poder. 


\section{REFERÊNCIAS:}

BAKHTIN, M. Estética da criação verbal. Trad. Paulo Bezerra. São Paulo: Martins Fontes, 2003.

BAKHTIN, M. Problemas da poética de Dostoiévski. Trad. Paulo Bezerra. Rio de Janeiro: Forense Universitária, 2008.

BARTHES, R. Theory of the Text. In: YOUNG, R. Untying the Text: a Poststructuralist Reader. Boston: Routledge \& Keegan Paul, 1981. p. 31-47.

BRADLEY, A. C. A tragédia shakespeariana. Trad. Alexandre Feitosa Rosas. São Paulo: Martins Fontes, 2009.

BEATON, K. Hark! A Vagrant. 2006-2016. Disponível em: <http://www.harkavagrant. com/index.php>. Acesso em: 25 abr. 2019.

BEATON, K. From the desk of \#4: Kate Beaton. Texto publicado no blog Pizza Island no dia 05/04/2011. Disponível em: <https://pizzaisland.wordpress.com/2011/04/05/fromthe-desk-of-4-kate-beaton/>. Acesso em: 12 abr. 2019.

GARBER, M. Shakespeare After All. Anchor Books. New York. 2005.

HUTCHEON, L. Uma teoria da paródia: ensinamentos das formas de arte do século XX. Trad. de Tereza Louro Pérez. Lisboa: Edições 70, 1985.

HUTCHEON, L. Poética do pós-modernismo: história, teoria e ficção. Trad. Ricardo Cruz. Rio de Janeiro: Imago Editora, 1991.

KERMODE, F. A linguagem de Shakespeare. Trad. Barbara Heliodora. Rio de Janeiro: Record, 2006.

KRISTEVA, J. "The Bounded Text". In: Desire in language: a Semiotic Approach to Literature and Art. Trans. Thomas Gora, Alice Jardine, and Leon S. Roudiez (Ed.). Oxford: Blackwell, 1980.

KRISTEVA, J. Introdução à semanálise. Trad. Lúcia Helena França Ferraz. 2ed. São Paulo: Perspectiva, 2005.

MARRONE, D. Hark! Anachronism. Kate Beaton's Historiographic Metafiction. In: GRACE, D.; HOFFMAN, E. (Eds.) The Canadian Alternative: Cartoonists, Comics, and Graphic Novels. University Press of Mississipi, Chapter 12, p. 176-188, 2018. 
MAUTNER, C. "I'm a Careful Person": An Interview with Kate Beaton. The Comics Journal, 4 de novembro de 2015. Disponível em: <http://www.tcj.com/im-a-carefulperson-an-interview-with-kate-beaton/>. Acesso em: 24 abr. 2018.

SANDERS, J. Adaptation and appropriation. New York: Routledge, 2006.

SILLIN, S. "I Can Dig It": Kate Beaton's C19 Punch Lines. J19: The Journal of Nineteenth-Century Americanists, Volume 5, Number 2, Fall 2017, p. 194-204.

VIEIRA, E. V. C. Espectralizações de Hamlet: aproximações entre a teoria da tradução e a apropriação literária. Revista Literatura em Debate, v. 6, n. 11, p. 168-189, dez. 2012. 